\title{
Variability of initial growth, water-use efficiency and carbon isotope discrimination in seedlings of Faidherbia albida (Del.) A. Chev., a multipurpose tree of semi-arid Africa. Provenance and drought effects
}

\author{
Olivier Roupsard ${ }^{\mathrm{a}}$, Hélène I. Joly ${ }^{\mathrm{a}}$, Erwin Dreyer ${ }^{\mathrm{b} *}$ \\ "CIRAD-Forêt, Campus international de Baillarguet, BP 5035, \\ 34032 Montpellier cedex 01, France \\ ${ }^{b}$ Inra-Nancy, UR Ecophysiologie forestière, Equipe bioclimatologie \\ et écophysiologie forestière, 54280 Champenoux, France.
}

(Received 28 May 1997; accepted 21 August 1997)

\begin{abstract}
The panafrican provenances of Faidherbia albida display contrasting growth and survival rates in semi-arid zones of western Africa, when they are compared in multi-local field trials. In order to identify some potential causes for such differences, we recorded the genetic variability of ecophysiological traits (including water-use efficiency, $W$, and carbon isotope discrimination, $\Delta$ ) in seven provenances from contrasting habitats of western and south-eastern Africa. Provenance and drought effects were tested on potted seedlings in a greenhouse. After 6 months, the total dry mass of the well-irrigated seedlings ranged from 31 to $86 \mathrm{~g}$, and the total water-use from 8 to $18 \mathrm{~kg}$. Both initial growth and water consumption were strongly correlated with leaf area. $W$ displayed a significant inter-provenance variability, and exhibited the highest values in the south-east African provenances, which were the most vigourous, but also presented the poorest survival rates in field trials. It was negatively correlated with the leaf-to-total dry mass ratio, LMR, and to $\Delta$. The mild drought significantly reduced gas-exchange rates, leaf area, growth, water-use, specific leaf area, and $\Delta$, in all provenances. It also increased the intrinsic water-use efficiency, $A / g$, and the root-to-total dry mass ratio, but did not affect $W$ or LMR. No provenance $\times$ drought interaction was found in any variable. The initial rate of leaf area establishment probably plays a major role in explaining the contrasting water-use strategies of the provenances. (C Inra/Elsevier, Paris.)
\end{abstract}

water-use efficiency / carbon isotope discrimination / Faidherbia albida / intraspecific variability

\footnotetext{
* Correspondence and reprints

E-mail: dreyer@nancy.inra.fr
} 
Résumé - Variabilité de la croissance initiale, de l'efficience d'utilisation de l'eau, et de la discrimination isotopique du carbone de plantules de Faidherbia albida (Del.) A. Chev., un arbre à usages multiples d'Afrique semi-aride. Effets provenance et sécheresse. Les provenances panafricaines de Faidherbia albida présentent des taux de croissance et de survie très inégaux dans les essais multilocaux pratiqués dans les zones sèches d'Afrique de l'Ouest. Afin d'identifier l'origine de ces différences, nous avons enregistré la variabilité génétique de caractères écophysiologiques (incluant l'efficience d'utilisation de l'eau, $W$, et la discrimination isotopique du carbone, $\Delta$ ) de semis issus de sept provenances d'Afrique occidentale et australe. Les effets provenance et sécheresse ont été testés en serre, sur des plantules en pot. La biomasse totale par plante des témoins bien irrigués a varié entre 31 et $86 \mathrm{~g}$, et la consommation d'eau entre 8 et $18 \mathrm{~kg}$. La croissance initiale et la consommation d'eau étaient toutes deux corrélées à la surface foliaire. $W$ a montré des différences significatives entre provenances, les valeurs étant plus élevées pour les provenances les plus vigoureuses. $W$ était corrélée négativement à LMR (rapport biomasse foliaire/biomasse totale), ainsi qu'à $\Delta$. La sécheresse a réduit significativement les échanges gazeux, la surface foliaire, la consommation d'eau, SLA (rapport surface sur masse foliaire), et $\Delta$. Elle a également augmenté l'efficience intrinsèque d'utilisation de l'eau (A/g), RMR (biomasse racinaire sur totale), mais n'a pas affecté $W$, ni LMR. Aucune variable n'a présenté d'interaction provenance $\times$ sécheresse. La vitesse d'installation de la surface foliaire est apparue essentielle pour comprendre les stratégies d'utilisation de l'eau de ces provenances. (@ Inra/Elsevier, Paris.)

efficience d'utilisation de l'eau / discrimination isotopique du carbone / Faidherbia albida / sécheresse / variabilité intraspécifique

\section{Abbreviations}

$a, b:{ }^{13} \mathrm{CO}_{2}$ discrimination coefficients for diffusion through stomata and fixation in $\mathrm{C}_{3}$ plants, respectively;

$A$ : net $\mathrm{CO}_{2}$ assimilation rate $\left(\mu \mathrm{mol} \mathrm{m} \mathrm{m}^{-2} \mathrm{~s}^{-1}\right)$; $A / g$ : intrinsic water-use efficiency $\left(\mu \mathrm{mol} \mathrm{mol}^{-1}\right)$; $C_{\mathrm{a}}, \mathrm{C}_{\mathrm{i}}$ : mole fraction of $\mathrm{CO}_{2}$ in the atmosphere and in the substomatal chambers, respectively $\left(\mu \mathrm{mol} \mathrm{mol}{ }^{-1}\right)$;

DIA: diameter at collar $(\mathrm{mm})$;

$\Phi_{\ldots}$ : proportion of net assimilated carbon lost through respiration, allocation to symbionts or exudation;

$\Phi w:$ proportion of water lost independently of photosynthesis;

FWU: final water-use during the last days of

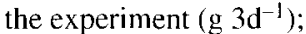

$g$ : stomatal conductance to water vapour $\left(\mathrm{mmol} \mathrm{m} \mathrm{m}^{-2} \mathrm{~s}^{-1}\right)$;

$H$ : final height $(\mathrm{cm})$

$k$ : plant carbon content $(\%)$;

LAR: leaf area-to-total dry mass ratio $\left(\mathrm{m}^{2} \mathrm{~kg}^{-1}\right)$;

LDM: leaf dry mass (g);

LMR: leaf-to-total dry mass ratio;

$v$ : water vapour mole fraction difference between substomatal evaporation sites and atmosphere $\left(\mathrm{mmol} \mathrm{mol}^{-1}\right)$;

PFD: PAR incident photosynthetic photon flux density $\left(\mu \mathrm{mol} \mathrm{m} \mathrm{m}^{-2} \mathrm{~s}^{-1}\right)$;
RDM: root dry mass (g);

RLA: root dry mass-to-leaf area ratio $\left(\mathrm{g} \mathrm{m}^{-2}\right)$;

RMR: root-to-total dry mass ratio;

$R_{\text {plant }}, R_{\text {air }}, R_{\text {maize }}$ : carbon isotope ratio of the plant, the atmosphere, and of maize (grown among the seedlings), respectively;

SDM: stem + branch dry mass (g);

SLA: specific leaf area $\left(\mathrm{m}^{2} \mathrm{~kg}^{-1}\right)$;

Subscripts ${ }_{H}$ and ${ }_{L}$ denote values measured under high and low irradiance, respectively;

SMR: shoot-to-total dry mass ratio;

TDM: total dry mass (g);

TLA: total leaf area $\left(\mathrm{m}^{2}\right)$;

TWU: total water-use, including transpiration and soil evaporation $(\mathrm{kg})$;

$W$ : water-use efficiency, or total dry mass-tototal water-use ratio $\left(\mathrm{g}_{\mathrm{DM}} \mathrm{kg}_{\mathrm{H}_{20}{ }^{-1}}\right.$ );

$\Delta$ : plant carbon isotope discrimination $(\%$, .

\section{INTRODUCTION}

Faidherbia albida (Del.) A. Chev. (syn. Acacia albida Del., Mimosoideae) is a wide spread African leguminous tree of great value for agroforestry, distributed in arid to semi-arid regions [37]. Mature trees of Faidherbia albida are famous for their 
peculiar reverse phenology. The adults are in leaf, growing and fruiting during the dry season, and leaves are shed after the first rains of the wet season. These features are highly valuable for agroforestry systems: this multi-purpose tree provides fodder during dry seasons, and does not compete for water or light with traditionally associated crops during the wet season.

Contrasting habitats are reported for this species: agroforestry parklands in western Africa, or natural riparian ecosystems in southern and eastern Africa. The wide distribution of $F$. albida implies a large genotypic variability: this was confirmed by genetic studies [22]. Panafrican seeds were collected, and several multilocal field trials were dedicated to the selection of the most interesting provenances $[2,15,30-32]$. These field trials consistently revealed a better initial shoot growth of the south-east African versus the west African provenances. However, when such trials were conducted in arid zones, the south-east African provenances were usually overcome during the following years and displayed a severe mortality $[1,2]$. In addition, the rankings of provenances for initial growth and for survival were strongly modified depending on the localization of the trials. This suggests the occurrence of important genotype $\times$ environment interactions for initial growth $[2,30]$ and for survival ability [2] under semi-arid conditions.

We tested the hypothesis that the contrasting vigour and survival observed on juveniles in the field could find expression in different water-use strategies. Very few results were available on the water relations of $F$. albida, and the genetical variability of ecophysiological traits related to water economy remains unexplored. F. albida is most probably a drought avoiding species displaying a phreatophytic strategy [35]. Optimal growth of the trees probably relies on an efficient root system giving access to deep water reservoirs $(-30 \mathrm{~m},[6])$, rather than on intrinsic drought tolerance. As a matter of fact, we observed rapid stomatal closure and leaf shedding on potted plants during the onset of water stress (unpublished data). Juveniles in the field probably have to cope with severe water deficits before reaching the water-table, and their initial shoot growth is usually very slow. For instance, heights reached after 5.5 years were only around $200 \mathrm{~cm}$ for the best provenances during two field trials in Burkina-Faso [1]. Their survival could thus rely on the efficiency of the root growth [32], and on the water-use strategy adopted before reaching groundwater.

Initial growth, root development and water economy of young $F$. albida are therefore expected to be crucial features for explaining the contrasting performances of the provenances during multilocal field trials, and for orientating the current selection programmes. This statement incited us to record ecophysiological traits associated with growth and transpiration, in seedlings from seven panafrican provenances, displaying contrasting growth strategies. Their response to limited water-supply was assessed. The wateruse efficiency $(W)$ was measured concurrently with other classical selection criteria. The use of $W$ as a selection criterion for provenances or genotypes can be of interest if several conditions are met: i) the occurrence of a significant intraspecific variability in initial growth as well as in $W$; ii) no negative interactions between $W$ and growth; iii) the strong heritability in $W$ [18]; and iv) a good knowledge of genotype $\times$ environment interactions influencing $W$. The present study was aimed at testing the first two conditions in $F$. albida.

The experiments were run in a greenhouse at Inra-Nancy (France). Measurements focused on growth features, wateruse efficiency, and photosynthetic 
performance. We tested the potential use of carbon isotope discrimination as a tool for investigating intraspecific variability of $W$ in this species. Our objectives were:

to assess the variability of growth, water consumption, and of a large range of ecophysiological variables among $F$. albida provenances, including $W$;

to check for drought effects, and provenance $\times$ drought interactions;

to derive some interpretations of the field trials results, and to propose some prospects for future selection.

\section{MATERIALS AND METHODS}

\subsection{Experimental set-up}

Seven panafrican Faidherbia albida provenances were selected (table I). They displayed contrasting initial growth and survival rates during field trials in dry zones in Burkina-Faso [1]. Each provenance was prepared from bulked seed-lots including a minimum of 20 progenies, and provided by various institutes.

In April 1994, seeds were soaked in $\mathrm{H}_{2} \mathrm{SO}_{4}$ $98 \%$ for $20 \mathrm{~min}$, bubbled for $24 \mathrm{~h}$, and then sown in individual $5 \mathrm{~L}$ containers, filled with a $1 / 2 \mathrm{v} / \mathrm{v}$ non-sterile peat/sand mixture. Pots were fertilized with oligo-elements (Kenieltra, France), and Nutricote 100 (slow release granules, N/P/K 13/10/10, Fertil, France). Seedlings were grown for 6 months in a greenhouse at Inra-Nancy (France), under natural daylight. Each provenance comprised 20 seedlings in individual pots which were distributed according to a completely randomized design and redistributed after every watering.

\subsection{Evapotranspiration}

Planted pots, and control (plant-free) pots were maintained at field capacity (water content $=0.25 \mathrm{~g}_{\mathrm{H}_{2} \mathrm{O}} \mathrm{g}_{\mathrm{soil}}{ }^{-1}$ ) by weighing and adjusting every $3 \mathrm{rd}$ day. Direct soil evaporation was limited with a waxy cardboard cover. Maximal soil evaporation was estimated from the water losses of five control pots (during the same period of the following year, at the same place, within a similar $F$. albida trial). The total 6-month evaporation of the control pots was $860 \pm 88 \mathrm{~g}$ (mean $\pm \mathrm{SD}$ ) as compared to the range $6160-18100 \mathrm{~g}$ recorded with seedlings. Since plant-free pots remained closer to field capacity than the planted ones and were not shaded by canopies, this value certainly overestimated the actual soil evaporation from planted pots. We checked that subtracting this maximal evaporation value from the measured evapotranspiration values (TWU) did not change the ranking and the provenance and drought effects for $W$ (water-use efficiency). We therefore computed $W$ using non-corrected estimates of transpiration.

Table I. Main characteristics of the seven provenances of Faidherbia albida tested (from Bastide and Diallo [1]).

\begin{tabular}{lccccc}
\hline Name/Country & Source & Latit & Longit & Elevat (m) & Rain (mm) \\
\hline Gihanga (Gih)/Burundi & $\mathrm{a}$ & $03^{\circ} 15 \mathrm{~S}$ & $29^{\circ} 15 \mathrm{E}$ & 800 & 650 \\
Mana-Pools (Man)/Zimbabwe & $\mathrm{a}$ & $15^{\circ} 45 \mathrm{~S}$ & $29^{\circ} 20 \mathrm{E}$ & 360 & 730 \\
Matameye (Mat)/Niger & $\mathrm{a}$ & $13^{\circ} 25 \mathrm{~N}$ & $08^{\circ} 28 \mathrm{E}$ & 450 & 560 \\
Kagnabon (Kag)/Senegal & $\mathrm{a}$ & $13^{\circ} 36 \mathrm{~N}$ & $16^{\circ} 40 \mathrm{~W}$ & 48 & 1000 \\
Mora (Mor)/Cameroon & $\mathrm{a}$ & $10^{\circ} 58 \mathrm{~N}$ & $14^{\circ} 12 \mathrm{E}$ & 450 & 780 \\
Dossi (Dos)/Burkina-Faso & $\mathrm{b}$ & $11^{\circ} 30 \mathrm{~N}$ & $03^{\circ} 25 \mathrm{~W}$ & 300 & 900 \\
Kongoussi (Kon)/Burkina-Faso & $\mathrm{c}$ & $13^{\circ} 30 \mathrm{~N}$ & $01^{\circ} 50 \mathrm{~W}$ & 338 & 600 \\
\hline
\end{tabular}

Provenances were ranked in decreasing order of total dry mass, after 6 months of growth in a greenhouse. a, CIRAD-Forêt, Montpellier, France; b, INERA-Productions Forestières, Ouagadougou, Burkina-Faso; c, CNSF, Ouagadougou, Burkina-Faso. 


\subsection{Drought}

Half of the seedlings were submitted to water shortage during the last 2 months, by letting the soil water content decline freely down to $0.15 \mathrm{~g}_{\mathrm{H}_{2} \mathrm{O}} \mathrm{g}_{\text {soil }}{ }^{-1}$ and maintaining it close to this level, as described above.

\subsection{Gas exchange analysis}

Leaf-gas exchange was measured after the onset of drought. Net $\mathrm{CO}_{2}$ assimilation rates $(A)$ and stomatal conductance for water vapour (g) were measured in situ. During bright days, between 12 and $15 \mathrm{~h}$, a twig with approximately ten fully-expanded leaves was inserted into a portable LiCor 6200 chamber (LiCor, Lincoln, USA). Mean $( \pm$ SD) climate conditions in the chamber were: air temperature: $29.3 \pm 3.0^{\circ} \mathrm{C} ; v$, water vapour molar fraction deficit: $23.8 \pm 4.8 \mathrm{mmol} \mathrm{mol}^{-1}$; $\mathrm{Ca}: 358.8 \pm 9.2$

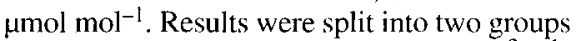
of irradiance: high ( $020 \pm 90.3 \mu \mathrm{mol} \mathrm{m}^{-2} \mathrm{~s}^{-1}$ ) and low irradiance $\left(349 \pm 32.4 \mu \mathrm{mol} \mathrm{m}^{-2} \mathrm{~s}^{-1}\right)$. The computation of $\mathrm{C}_{\mathrm{i}}\left(\mathrm{CO}_{2}\right.$ molar fraction in the substomatal chambers, $\mu \mathrm{mol} \mathrm{mol}^{-1}$ ) was performed according to Von Caemmerer and Farquhar [34]. $A$ and $g$ were reported to the projected leaf area, owing to the lack of information about the relative contribution of the two faces of these amphistomatous leaves to gas exchange.

\subsection{Growth variables and carbon isotope analysis}

Height and water consumption of all potted seedlings were monitored till the age of 6 months. The plants were harvested and ovendried $\left(80^{\circ} \mathrm{C}, 48 \mathrm{~h}\right)$, and the dry mass of each compartment (leaves, roots, branches + stems) measured. Leaf area was measured with a $\Delta \mathrm{T}$ area-meter ( $\Delta \mathrm{T}$ Devices, Hoddesdon, UK). Total leaf area (TLA) of the plants was estimated from the specific leaf area (SLA) of a sample of 30 randomly selected leaves per plant.

Plants were then ground to a fine powder. Samples of total dry mass were burned in a pure $\mathrm{O}_{2}$ atmosphere, for the quantitative conversion of $\mathrm{C}$ into $\mathrm{CO}_{2}$. The determination of the ${ }^{13} \mathrm{C} /{ }^{12} \mathrm{C}$ isotope ratio $(R)$ was made by mass spectrometry in the 'Laboratoire central d'analyses, CNRS' (Solaize, France).

\subsection{Photosynthesis and carbon isotope discrimination}

In order to compute carbon isotope discrimination $(\Delta)$, we used the expression of Farquhar and Richards [8]:

$$
\Delta=\frac{\left(R_{\mathrm{air}}-R_{\mathrm{plant}}\right)}{R_{\mathrm{plant}}}=\frac{\delta_{\mathrm{air}}-\delta_{\text {plant }}}{1+\delta_{\text {plant }}}
$$

$R_{\text {plant }}$ and $R_{\text {air }}$ are the carbon isotope ratios of the plant and the atmosphere, respectively, and $\delta$ is the carbon isotope composition relative to the Pee Dee Belemnite Standard.

We checked that $R_{\text {air }}$ was constant during the experiment. In order to estimate $R_{\text {air }}$, maize grains were sown at four dates in similar pots, among the $F$. albida seedlings, and their fourth leaf collected 2.5 months later (4 sowing and harvest dates, 2-4 repetitions/harvest date). $\delta_{\text {maize }}$ values did not vary much during the 6 months, $(n=13$; mean $=-11.36 \pm 0.45 \%$ ). This mean value of $\delta_{\text {maize }}$ was thus used for estimating $\delta_{\text {air }}$ from equation (4) [24]:

$$
\delta_{\text {air }}=3.276+\delta_{\text {maize }}
$$

Our experimental value of $\delta_{\text {air }}(-8.69 \%$ c $)$ was close to typical values $(-8.00 \%,[10])$.

At an instantaneous scale, the intrinsic water-use efficiency $A / g$ (i.e. the ratio of net $\mathrm{CO}_{2}$ assimilation to leaf conductance to water vapour) usually provides a good estimation of $C_{\mathrm{i}} / C_{\mathrm{a}}$ (the set-point for gas-exchange), and influences $\Delta$. Instant and simplified relationships for $\mathrm{C}_{3}$ plants were presented by Farquhar et al. [9]:

$$
\frac{A}{g}=\frac{C_{\mathrm{a}}}{1.6} \cdot \frac{(b-\Delta)}{(b-a)}
$$

where $A / g$ is the intrinsic water-use efficiency; $C_{\mathrm{a}}$ is the mole fraction of $\mathrm{CO}_{2}$ in the atmosphere; 1.6 is the ratio of conductance for $\mathrm{H}_{2} \mathrm{O}$ and $\mathrm{CO}_{2} ; \Delta$ is the carbon isotope discrimination; and $a, b:{ }^{13} \mathrm{CO}_{2}$ discrimination coefficients for diffusion through stomata $(a=4.4)$, and fixation $(b=27)$ in $\mathrm{C}_{3}$ plants [9].

$\Delta$ in the accumulated biomass, therefore, provides a time-integration of $C_{\mathrm{i}} / C_{\mathrm{a}}$, and $A / g$. $A / g$ is also expected to influence $W$, the time- 
integrated water-use efficiency. $\Delta$ can thus be correlated with $W$ during short periods of time, provided that $v, \Phi_{c}$, and $\Phi_{w}$ are non-disruptive elements, according to the general model developed by Farquhar and Richards [8], and Farquhar et al. [10]:

$$
W_{t}=\frac{C_{a}}{1.6 \cdot v} \cdot \frac{b-\Delta}{b-a} \cdot \frac{\left(1-\phi_{i}\right)}{\left(1+\phi_{w}\right)} \cdot \frac{2}{3 k}
$$

where $W_{\mathrm{t}}$ is the transpiration efficiency; $v$ is the water vapour mole fraction difference between substomatal evaporation sites and atmosphere; $\Phi_{c}$ is the proportion of net assimilated carbon lost through respiration, allocation to symbionts or exudation; $\Phi_{w}$ is the proportion of water lost independently of photosynthesis; $k$ is the carbon content relatively to total biomass and $2 / 3$ is the molecular mass ratio of $\mathrm{C}$ to $\mathrm{H}_{2} \mathrm{O}$.

\subsection{Statistical analysis}

The inter-provenance variability was analysed using the following two methods.

All measured variables were described globally for their structure (correlations, main sources of variation). A principal component analysis (PCA) was performed on 17 time-integrated growth and six instantaneous gasexchange variables, using centred-reduced values, corresponding to the means of the 14 (7 provenances $\times 2$ watering regimes) treatments. The reliability of this PCA was assessed as follows: even distribution of individuals on the principal component plots; axes characterized by a homogeneous set of individuals; $\Sigma r^{2}$ and $\Sigma \cos ^{2}$ larger than 0.5 (for the correlations between variables and individuals with the main axes, respectively).

The most relevant variables were analysed separately (ANOVA) to test the significance of provenance and drought effects. The whole statistical display was completely randomized and bivariate (provenance $\times 7$; water-supply $\times 2$ ), with $7-10$ replications for the whole experiment. It was trivariate for gas-exchange analysis, since a third factor (irradiance $\times 2$ ) was tested, with 3 to 8 replications. The ANOVA was computed for each variable with the SAS statistical package (SAS Institute Inc., 1988) using the General Linear Model. Variance homogeneity and distribution of residues were checked, and variables eventually trans- formed into logarithm (In) or square-root (root) to match these conditions. Homogeneous groups were defined using Bonferroni's test.

\section{RESULTS}

\subsection{Height growth}

Germination time and growth kinetics were similar among provenances. Plants showed typical sigmoid-shaped height growth curves during the 6-month experiment (figure l). The differences in initial growth expected between provenances were achieved: the most vigorous ones, Man and Gih (south-eastern Africa) reached more than $100 \mathrm{~cm}$, i.e. nearly twice the height of the smallest (Dos and Kon; western Africa). The slow-down of growth was synchronized in all provenances, irrespective of the height and biomass accumulated, and was therefore probably not pot-bound or nutritionally induced. Nevertheless, it could not be unequivocally attributed to environmental (temperature, photoperiod) or genetical effects. Drought reduced height growth of all provenances by around $6-14 \%$, with the exception of Mor (only $1 \%$ ).

\subsection{Provenance effects}

A large inter-provenance variability was found for most variables (table IIa, $b$ ). Provenance effects were all significant $(P<0.05)$ to highly significant $(P<0.001)$, with a few exceptions, i.e. the carbon fraction in dry matter $(k)$ and the intrinsic water-use efficiency $(A / g)$. Intra-provenance variability cumulated with error $\left(1-r^{2}\right)$ remained quite high for most variables, e.g. $39 \%$ for TDM, $69 \%$ for $\Delta$, and $50 \%$ for $W$. Several rankings of provenances could be established. 


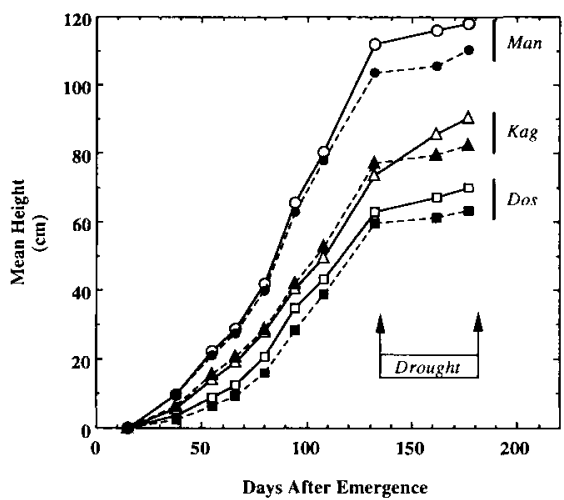

Figure 1. Height growth kinetics of potted seedlings of Faidherbia albida from three provenances (Man, Zimbabwe; Kag, Senegal; Dos, Burkina-Faso) during 6 months in a greenhouse. Open symbols: well-watered plants; closed symbols: droughted plants. Drought was imposed during the last period. Vertical bars represent SD for each provenance at harvest. $N=7-10$ replicates per treatment.

\subsubsection{Vigour}

Figure 2 illustrates the ranking obtained among provenances for total dry mass (TDM), total water-use (TWU), and wateruse efficiency $(W)$ :

$$
\begin{gathered}
{[\text { Man, Gih }] \geq[\text { Mat, Kag }] \geq} \\
{[\text { Mor }] \geq[\text { Dos, Kon }]}
\end{gathered}
$$

Means decreased from the south-eastern African provenances (Gih, Man) to the western ones (Mat, Kag, Mor, Dos, Kon). However, there was no correlation between this ranking and the amount of rainfall reported in the geographic origin of the provenances (table I). The above ranking was also valid for variables of vigour, including the dry mass of each compartment (RDM: root; SDM: shoot; LDM: leaf), $\mathrm{H}$ (height), TLA (total leaf area), DIA (diameter at collar), and SLA (specific leaf area). Two important variables

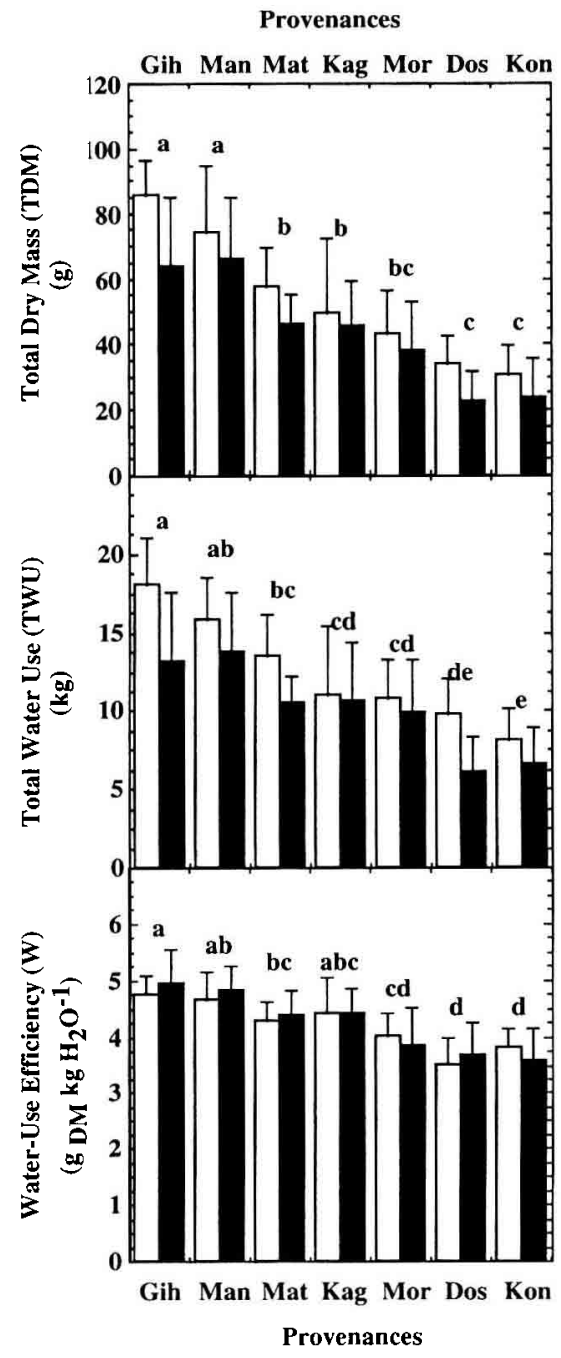

Figure 2. Total dry mass (TDM), total wateruse (TWU), and water-use efficiency $(W)$ of potted seedlings from seven provenances of Faidherbia albida after 6 months of growth in a greenhouse. Seedlings were either wellwatered (open bars) or droughted (dark bars). Statistics correspond to the well-watered treatment: means with the same letter were not significantly different $(\alpha=0.05)$, and no provenance $x$ watering regime interactions were recorded. Error bars indicate SD. For the list of provenances, see table $I . N=7-10$ replicates per treatment. 


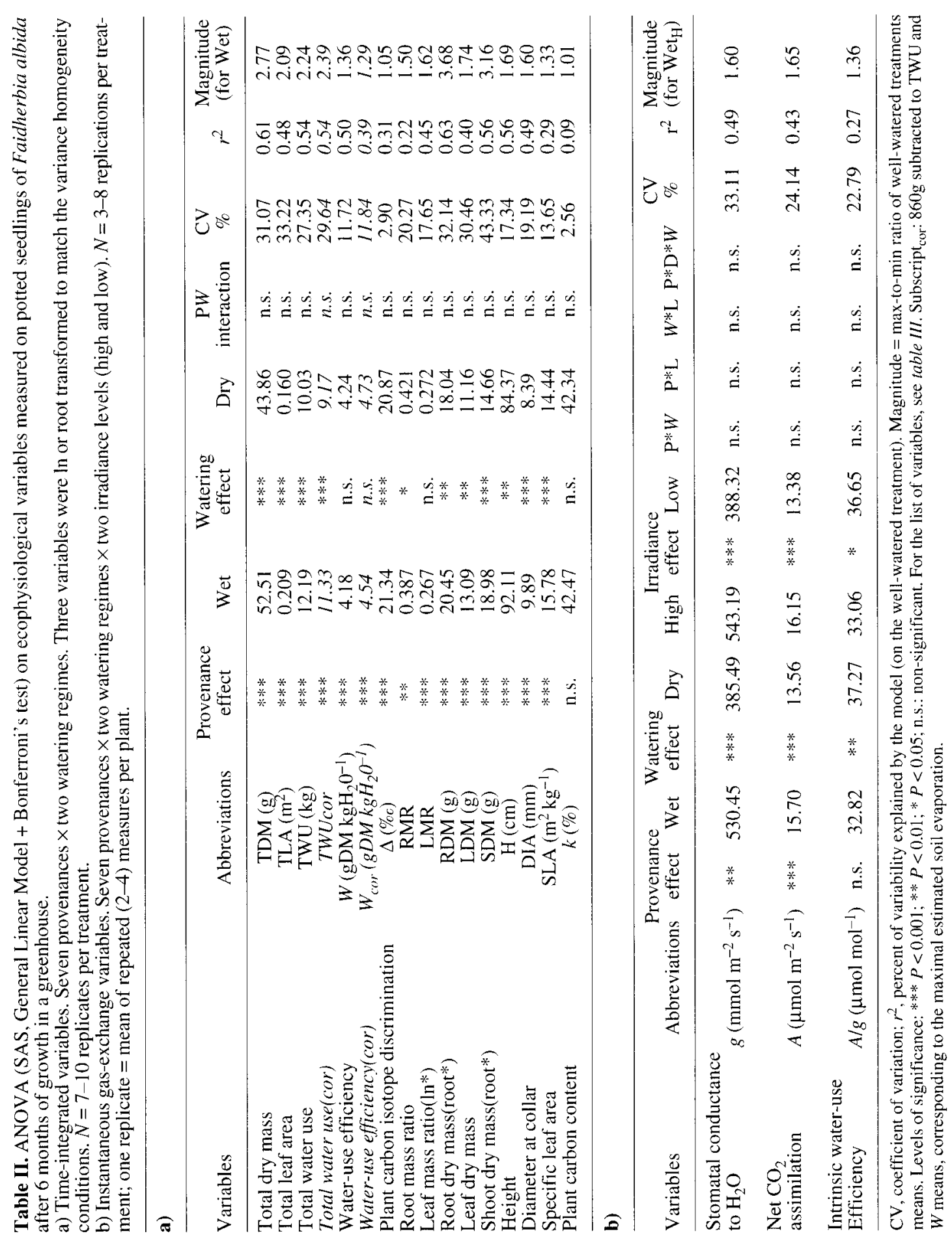


yielded an opposite ranking: LMR (leaf-tototal dry mass ratio) and $\Delta$ (carbon isotope discrimination).

The magnitude of the variability among means of well-irrigated provenances was 2.8 for TDM and 2.2 for TWU. The magnitude was lower for LMR (1.6) and $W$ (1.36), and weak for $\Delta$ (1.05, corresponding to a maximum difference of 1.1 per mil units).

\subsubsection{Gas-exchange rate}

Provenance effects were significant for the stomatal conductance $(g)$ and the net assimilation per unit leaf area $(A)$, but not for the intrinsic water-use efficiency $(A / g)$ (table IIb). $A$ and $g$ were lower in the most vigorous provenances (Gih, Man, southeast Africa) but the ranking for gas exchange was not fully converse to the one for vigour:

$$
\begin{aligned}
{[\text { Mor }] \geq } & {[\text { Kag, Dos, Mat, Kon }] } \\
& \geq[\text { Man, Gih }]
\end{aligned}
$$

In situ measurements revealed rather high levels of $A$ and $g$ per unit leaf area (around 15-20 $\mu \mathrm{mol} \mathrm{m}^{-2} \mathrm{~s}^{-1}$ and up to $600 \mathrm{mmol} \mathrm{m}^{-2} \mathrm{~s}^{-1}$, respectively). The magnitude of variation for $A_{\text {Hwet }}$ or $g_{\text {Hwet }}$ (high irradiance, well-watered) was close to 1.6. It was still 1.36 for $A / g_{\text {Hwet }}$ but no significant provenance effect could be detected in this trait. Thicker leaves displayed higher $A$ values: $59 \%$ percent of the variability in $A_{\mathrm{Hwet}}$ could be attributed to SLA.

\subsubsection{Root biomass fraction}

The root-to-total biomass ratio (RMR) was independent of vigour and gas exchange rate, and was not correlated with the amount of rainfall in the geographical origin of provenances, the ranking of provenances was:

[Gih] $\geq[$ Kon, Mor, Dos, Man] $\geq[$ Mat, Kag]

The magnitude was 1.5 for $\mathrm{RMR}_{\text {wet }}$.

\subsection{Drought effects}

Drought was only applied during the last third of the growth period. The drought stress intensity was estimated from the reduction in soil water content, from 0.25 (control) to 0.15 (dry) $\mathrm{g}_{\mathrm{H}_{2} \mathrm{O}}$ $\mathrm{g}_{\text {soil }}{ }^{-1}$. Predawn leaf water potential of droughted seedlings did not differ significantly from the control (data not shown), which demonstrates that water stress remained mild. The inter-provenance rankings presented above remained valid in the dry treatment and no provenance $x$ water-supply interactions were detected. Drought nevertheless affected almost all growth and gas exchange variables (table $I I a, b)$, with the exception of $W$, LMR and $k$. Drought reduced all vigour variables, from $-47 \%$ for FWU (final water-use) to $-8 \%$ for height. LDM was reduced by $15 \%$, TDM by $16.5 \%$, and as a result, LMR was kept almost constant. Drought reduced SLA in all provenances, but very slightly $(-8.5 \%$ globally and $-20 \%$ in Gih). The effects on $W$ and its determinants resulted in an unexpected discrepancy: $W$ remained unaffected by drought, while $\Delta$ was reduced. Drought reduced $g$ $(-28$ and $-29 \%$, under high and low irradiance, respectively) and $A(-14$ and $-17 \%)$, and as a result enhanced $A / g$ $(+14 \%$ and $11 \%)$. The increase of $A / g$ induced by drought was consistent with the observed reduction of $\Delta$. The root-tototal mass ratio (RMR) was moderately increased by drought (globally $+9 \%$ ). The stability of LMR and the increase of RMR clearly demonstrated a diversion of the biomass allocation from stems and twigs to roots during drought. RMR was increased in Mat, Kon and Dos by 25, 17 and $10 \%$, respectively, but much less in the other provenances.

\subsection{Main sources of variability, and correlations between variables}

The correlations between 17 time-integrated growth variables and six instanta- 
neous gas-exchange variables are shown in the correlation matrix, computed for the means of the 14 treatments ( 7 provenances $\times 2$ watering regimes, table (II). The main components of variability were defined by the variables best correlated with axis 1, 2 and 3 of the PCA (figure $3 a$ ). The reliability of the procedure was attested as follows: $75.1 \%$ of the total variability was accounted for by the first two axes, and $8.3 \%$ by axis 3 . All variables were well represented $\left(\sum r^{2}>0.5\right)$. RMR, $k$ (car- bon content), $A_{\mathrm{H}}$ (net assimilation in high light) and $A / g_{\mathrm{L}}$ (intrinsic water-use efficiency, in low light), were poorly represented, and displayed $\Sigma r^{2}$ values ranging from 0.25 to 0.5 . Three corresponding groups of intercorrelated variables are detailed below: [vigour] and [gasexchange rates], corresponding to axis 1 and axis 2, respectively, and [root biomass fraction] (third axis, not illustrated). These three groups of variables were not correlated together, by definition.
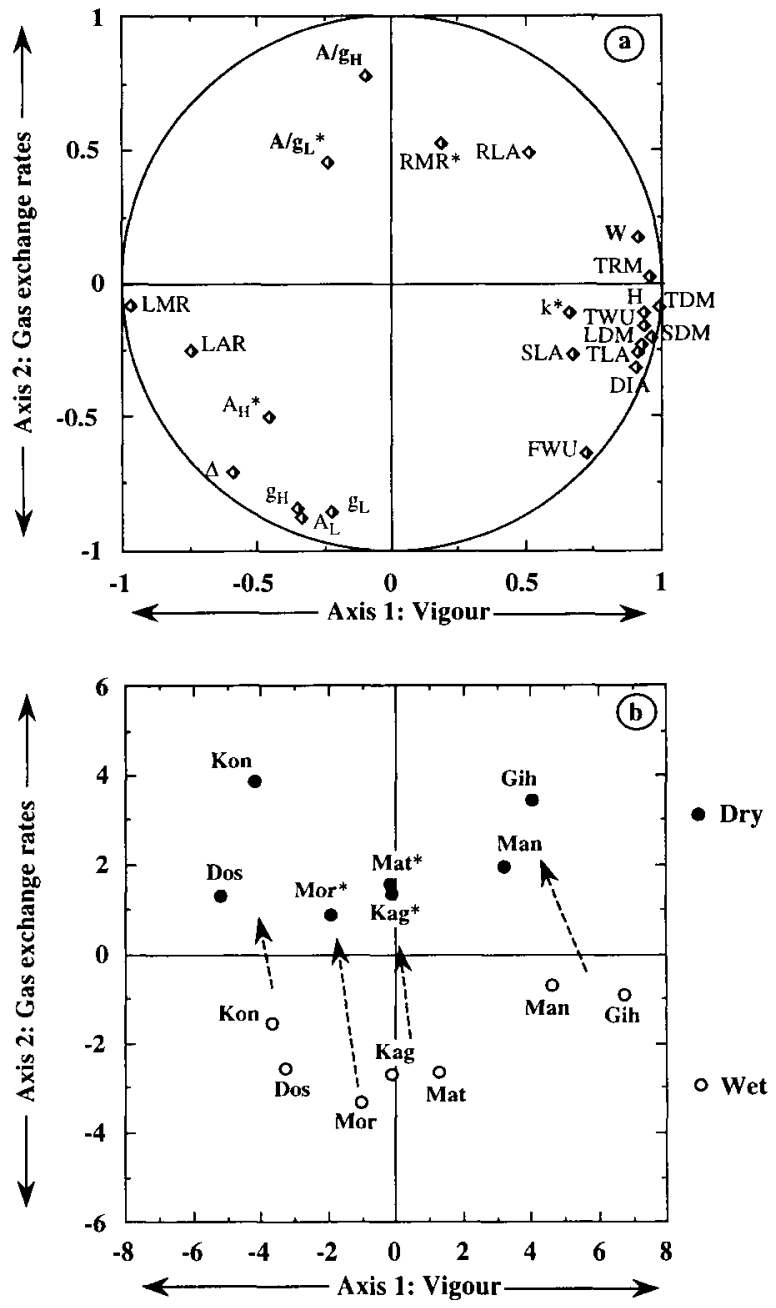

Figure 3. Principal component analysis $(75.1 \%$ of total variability represented by the axis1/axis 2 plot) of the total variability found in an experiment conducted on Faidherbia albida (seven provenances $\times$ two watering regimes) after 6 months of growth in a greenhouse. $\left(^{*}\right)$ Indicates poorly represented variables (figure $3 a$ : $\Sigma r^{2}<0.5$ ), or individuals (figure $3 b$ : $\Sigma \cos ^{2}<0.5$ ).

a) Distribution of 23 growth and gas exchange variables. For the list of variables, see table III.

b) Distribution of seven provenances $x$ two watering regimes. For the list of provenances, see table $I$. Seedlings were either wellwatered (open symbols) or droughted (dark symbols). Arrows indicate the changes induced by drought, i.e. a small reduction of vigour, and a large one of gas exchange. $N=7-10$ replicates per treatment. 


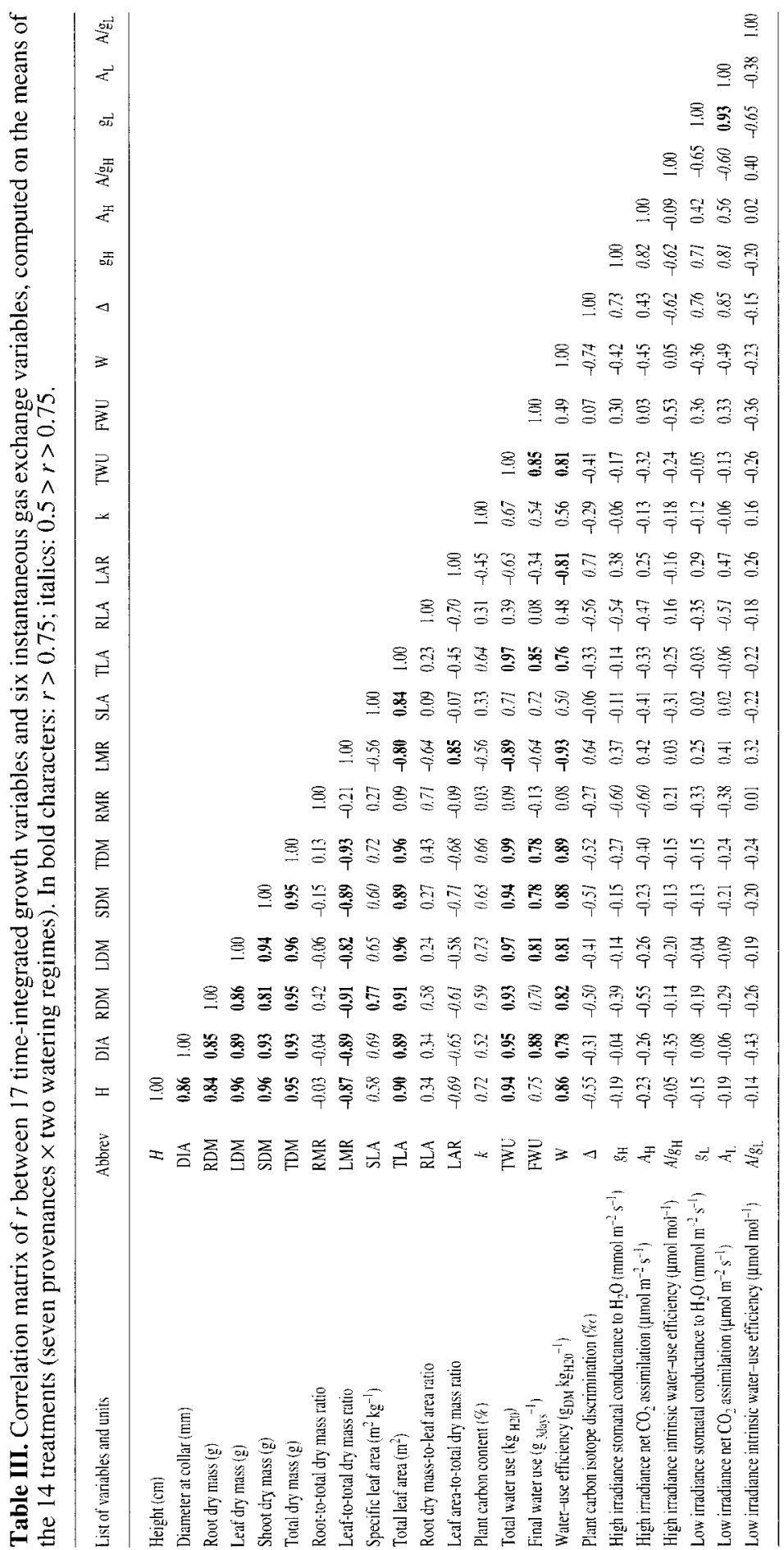




\subsubsection{Vigour group (Axis 1; 52.4\% of total variability explained)}

Variables best correlated with axis 1 (with $r^{2}>0.80$ ) were, in decreasing order: TDM, TWU, LMR (negatively correlated), RDM, H, SDM, LDM, TLA and DIA (diameter at collar). As a result, this axis was considered to represent globally the vigour of the seedlings. All these variables were also strongly correlated together $\left(n=14 ; 0.64<r^{2}<0.97\right.$; $P<0.001)$. Figure 4 illustrates this point with correlations between TLA, TDM and TWU, and clearly shows the strong impact of TLA in explaining vigour differences between provenances. Fast growing plants displayed larger, but also thinner leaves, since SLA was positively correlated with these vigour variables $(n=14$; $\left.0.32<r^{2}<0.70 ; 0.001<P<0.03\right)$. $W$ was positively correlated $(n=14$; $0.57<r^{2}<0.86 ; P<0.002$ ) with vigour variables, and $\Delta$ poorly and negatively $\left(n=14 ; 0.1<r^{2}<0.42 ; 0.012<P<0.28\right)$.

The 14 provenances $\times$ watering regimes clearly segregated along the vigour axis of the PCA presented in figure $3 b$, and most of them were well represented on the principal component axis 1/axis 2 plot $\left(\Sigma \cos ^{2}>0.5\right)$.

\subsubsection{Gas-exchange rate group (axis $2 ; 22.7 \%$ of total variability explained)}

Gas-exchange variables, best correlated with axis $2\left(r^{2}>0.7\right)$ were, in decreasing order: $A_{\mathrm{L}}$ (net assimilation under low irradiance), $g_{\mathrm{L}}$ and $g_{\mathrm{H}}$ (stomatal conductance to water vapour under both irradiance levels). They were independent of the vigour axis. Stomatal conductance was positively correlated with $A$, and both were negatively correlated with $A / g . \Delta$ was positively correlated with $g$ under both irradi-

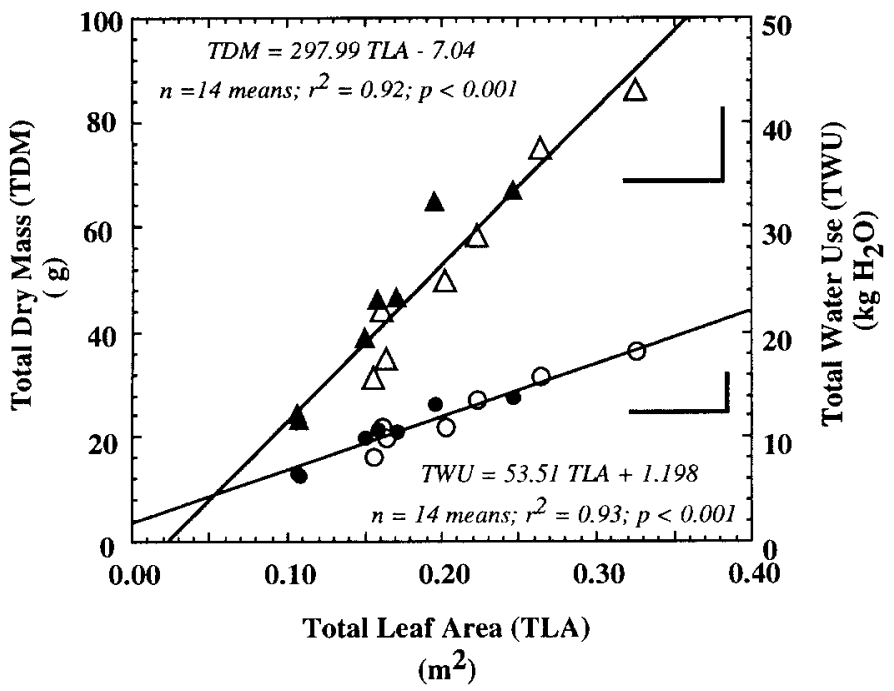

Figure 4. Relationships between mean values of total leaf area (TLA) and total dry mass (TDM, triangles), or total water-use (TWU, disks), as recorded on potted seedlings of Faidherbia albida (seven provenances $\times$ two watering regimes) after 6 months of growth in a greenhouse. Wellwatered plants: open symbols; droughted, dark symbols. For the list of provenances, see table $I$. Bars represent the mean SD for all variables. $N=7-10$ replicates per treatment. 
ances, positively with $A_{\mathrm{L}}(n=14$; $\left.0.18<r^{2}<0.72 ; P<0.01\right)$, and negatively with $A / g_{\mathrm{H}}\left(n=14 ; r^{2}=0.38 ; P=0.02\right)$.

The two watering regimes clearly segregated along the gas-exchange axis of the PCA presented in figure $3 b$. The drought effect was indicated by the direction of the arrows, resulting in a reduction of vigour, of gas-exchange rates and of $\Delta$, and in an increase of $\mathrm{A} / \mathrm{g}$.

\subsubsection{Root biomass fraction (axis 3; $8.3 \%$ of total variability explained)}

Root-to-total dry mass ratio (RMR) was correlated with axis 3 , with $r^{2}=0.53$, and not with vigour and gas-exchange variables.

\subsection{Correlation between water-use efficiency $(W)$ and its determinants}

$W$ was positively correlated with vigour, e.g. TDM and TWU figures 2 and 3) and negatively with LMR and $\triangle$. LMR and $W$ were both unaffected by drought, and a single negative correlation $(n=14$; $r^{2}=0.86 ; P<0.001$ ) between mean provenance values of $W$ and LMR could be drawn (figure $5 a$ ). On the opposite, two different negative regression lines between $W$ and $\Delta$ were evidenced for the two watering regimes (figure $5 b)(n=7$; $r_{\text {wet }}^{2}=0.69$ and $r_{\text {dry }}^{2}=0.92$; $0.001<P<0.021$ ). In each individual provenance, negative, but not always statistically significant, correlations between $W$ and $\Delta$ were found (data not shown).

No correlation was found between $\mathrm{A} / \mathrm{g}$ and $W$, but a negative one was found between $A / g_{\text {wet }}$ (measured under high irradiance, on the wet plants $)$ and $\Delta(n=7$; $r^{2}=0.56 ; P=0.05$ ) (figure 6).

We did not find any positive correlation between RLA (root dry mass-to-total leaf area ratio, which is potentially an estimator of the total soil-to-leaf hydraulic conductance), and $g, A / g$ or $W$.

\section{DISCUSSION}

\subsection{Provenance effects}

\subsubsection{Variability in vigour and allocation patterns}

A large inter-provenance variability of initial growth was found in F. albida seedlings under optimal water supply. The principal components of this variability were variables defining vigour, including total dry mass (TDM), leaf-to-total dry mass ratio (LMR, negatively correlated) and compartment biomasses (RDM, LDM, SDM for roots, leaves and stems + branches, respectively), total leaf area (TLA), height $(H)$, and diameter at collar (DIA). The magnitude of the total variability of the control plants was close to 2.8 for TDM, and 2.1 for TLA. The two south-east African provenances (Man, Gih) displayed a higher vigour than the west African ones. This ranking is consistent with the information gathered during diverse field trials or on potted seedlings, which showed better initial growth for diverse south-east African provenances [1, 15, 25, 30-32]. This observation suggests the occurrence of an important genetical determinism for vigour in this species. Slow-growing provenances however exhibited better survival rates during field trials in semi-arid zones $[1$, 2].

The physiological basis of such vigour differences was investigated using the correlations between dry matter accumilation (TDM) and $k$ (carbon content), $A$ (net assimilation rate), TLA (total leaf area), LMR (leaf-to-total mass ratio) and $\Phi_{c}$ (proportion of assimilated carbon lost through respiration, allocation to symbionts or exudation). TDM was neither 


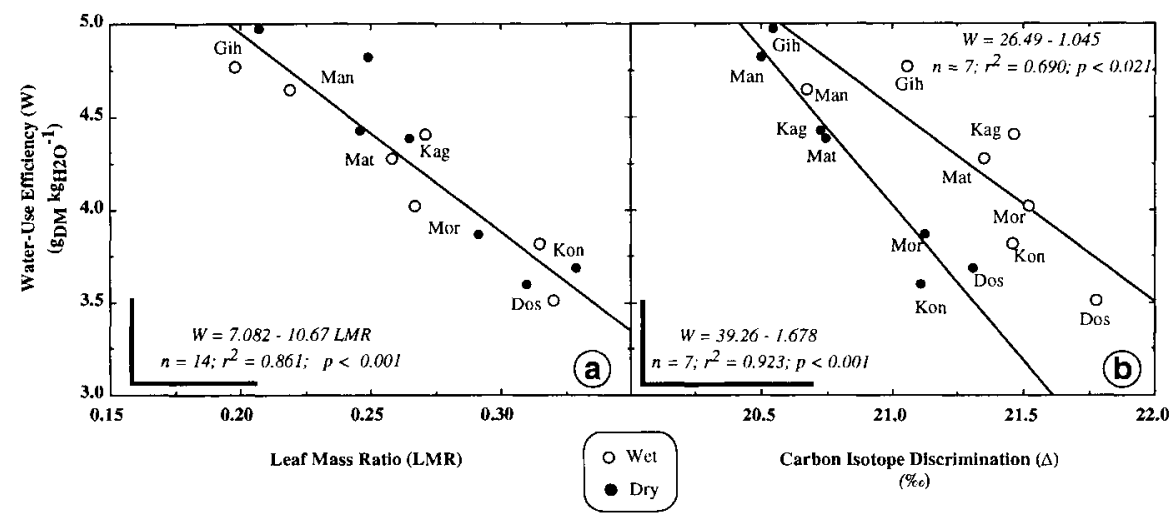

Figure 5. Correlations between mean water-use efficiency $(W)$ and a) leaf-to-total dry mass ratio LMR, b) plant carbon isotope discrimination $(\Delta)$, as recorded on the seedlings from seven provenances of Faidherbia albida, that were either well-watered (open symbols) or droughted (dark symbols), after 6 months of growth in a greenhouse. Error bars indicate a mean value of SD. For the list of provenances, see table $I . N=7-10$ replicates per treatment.

correlated to $k$, nor to $A$. Fast growing provenances displayed higher LDM and SLA (specific leaf area). As a result, $95 \%$ of the variability of TDM was explained by TLA. However, higher LDM was not due to a higher biomass allocation to the leaves, since LDM was negatively correlated to LMR and LAR (leaf-to-total biomass ratio, and leaf area-to-total dry mass ratio, respectively). Therefore, the differences in TDM could not be explained by differences in LMR and $A$. A negative correlation between biomass and LAR was similarly evidenced by Virgona et al. [33], with sunflower. These findings oppose to those obtained for 24 herbaceous species by Poorter and Remkes [28]. A current hypothesis under investigation is that they find their origin in differences of $\Phi_{c}$, and that these carbon losses are larger in slowgrowing provenances.

The magnitude of variation in TWU (total water-use) was 2.2 among provenances. TWU and FWU (final water-use) were positively correlated to TDM and TLA, but not to stomatal conductance $(g)$.
TLA was thus the key determinant of water-use by the different provenances.

Gas-exchange rates ( $A$ and $g$ ) were not correlated to vigour. Inter-provenance differences in the intrinsic water-use efficiency $A / g$, that is in $C_{\mathrm{i}} / C_{\mathrm{a}}$, were detected, but remained unsignificant, due mainly to a high intra-provenance variability $\left(1-r^{2}=63 \%\right)$.

\subsubsection{Variability in water-use efficiency $(W)$ and carbon isotope discrimination ( $\triangle$ )}

Recorded values of $W$ were within the range of values published for diverse plants grown in pots. Under very similar conditions (adjacent greenhouse), Guehl et al. [12] obtained values of $W$ ranging between 4 and $7 \mathrm{~g} \mathrm{~kg}^{-1}$ with seedlings of Pinus pinaster and Quercus robur. Ismail and Hall [19] reported similar levels (4.2-4.5) for cowpea (Vigna unguiculata). A number of reports presented much lower values for potted plants in the field (from 1.5 up to 2 with three provenances of 
Figure 6. Relationship between mean values of intrinsic water-use efficiency $(A / g$ measured under high irradiance, on the wellwatered plants), and carbon isotope discrimination $(\Delta)$, recorded on seedlings from seven provenances of Faidherbia albida in a greenhouse. Mean SD indicated by bars. For the list of provenances, see table I. $N=7-10$ replicates per treatment.

Eucalyptus camaldulensis, [16]; 2.5 up to 3.7 for peanut cultivars [38]). Experimental differences in water vapour pressure deficits $(v)$ or water losses not associated to photosynthesis (e.g. soil evaporation) make any direct comparison unreliable. The range of $W$ we found among provenances was around 1.35. Guehl et al. [13] reported a 1.25 range among several Pinus pinaster provenances, 1.4 among full-sib families of the best provenance of the same species, and Johnson et al. [21] reported 1.85 in Agropyron desertorum.

$\Delta$ of provenances ranged from 20.7 to $21.8 \%$ (well-watered plants). This is a rather small interval $(1.1 \%$ ), close to the difference observed among three provenances of Pinus pinaster (1.3\%o [13]), or among four full-sib families of Picea mariana (0.7-1\%o [11]), but smaller than those reported for five field-grown Coffee cultivars (1.6\%o [27]), for Pseudotsuga menziesii $(2.7 \%$, among 27 provenances [40]), or for Eucalyptus camaldulensis $(3.6 \%$, among three provenances [16]). We conclude from these observations that the variability for $W$ and $\Delta$ is relatively moderate in $F$. albida.

\subsection{Determinants of $W$ and $\Delta$}

\subsubsection{Correlations between $\mathrm{A} / \mathrm{g}$, $W$ and $\triangle$}

Differences in $\Delta$ were significant between provenances, confirming the occurrence of differences in $C_{\mathrm{i}} / C_{\mathrm{a}}$. Though $\Delta$ is an integrator of $A / g$ variations, it must be kept in mind that $\Delta$ values can be also influenced by differences in carbon allocation ( $\Delta$ of roots or shoots are usually smaller: $[17,41])$, by respiration, or by canopy effects. Nevertheless, $\Delta$ was negatively correlated with $A / g_{\mathrm{HW}}$ (high irradiance conditions, well-watered treatment) according to equation (3).

Unexpectedly, $W$ and $A / g$ were not correlated. This lack of correlation leads to the question of the significance of instantaneous measurements of $A$ and $g$ to explain a time-integrated variable like $W$. Several hints can affect this significance: i) was gas exchange, measured at the end 
of growth, representative of the whole lifespan of the seedlings? ii) measurements during the beginning of the afternoon may differ from those in the morning, particularly under stress conditions; iii) gas exchange was measured on lateral branches, under direct irradiance, whereas the whole leaf area of the largest provenances could have been more shadowed: since $A / g$ was larger under low irradiance, whole-plant $A / g$ could have been underestimated in these vigorous provenances, with respect to the smaller ones. Moreover, according to equation (4), $W$ is expected to be less closely related to $A / g$ than $\Delta: W$ can also be influenced by timevariations of $v$, or by differences of $\Phi_{c}$ and $\Phi_{w}$. The lack of correlation between $W$ and $A / g$ was therefore not a surprise.

\subsubsection{Correlations between $W, \Delta$, vigour and biomass allocation patterns}

Provenances displaying high initial growth, high water consumption and poor survival in arid zones also showed higher $W$. Similar results were achieved in genetic families of Pinus pinaster by Guehl et al. [13], in Eucalyptus camaldulensis [16], or in genotypes of Helianthus annuus [33]. The correlation between $W$ and leaf mass ratio (LMR) was tight. Guehl et al. [12] also found a negative correlation between W and LMR in Quercus petraea and Pinus pinaster, and Virgona et al. [33] reported a similar result in sunflower. LMR could thus be an interesting predictor of $W$ in $F$. albida.

$W$ was as expected negatively correlated with $\Delta[4,10]$.

A negative relationship was evidenced between $\Delta$ and vigour, similar to the one found by Guehl et al. [13] in Pinus pinaster, or by Donovan and Ehleringer [5] in Crysothamnus nauseosus. A negative correlation is expected between $\Delta$ and biomass when the influence of $A$ on $\Delta$ is prevalent over that of $g$, but in $F$. albida, $\Delta$ was correlated with both $A$ and $g$. On the contrary, many positive correlations were reported between $\Delta$ and vigour: in Lycopersicon sp. by Martin and Thorstenson [23], in wheatgrass by Johnson et al. [20], and in beans by White et al. [36]. As a matter of fact, the relationship between $\Delta$ and vigour can be completely reversed by changes in environment, and should therefore be used with care $[3,5]$.

It would be meaningful to look for positive correlations between $W, A / g$ and the soil-to-leaf hydraulic conductance $\left(g_{\mathrm{L}}\right)$ : we found no positive correlation between $W$ and RLA (root mass-to-leaf area ratio), but the latter is not always a good estimator of $g_{\mathrm{L}}$.

\subsection{Drought effects}

Although drought was moderate, and imposed only at the end of the growth phase, most of the variables were significantly affected, thus testifying that all provenances were sensitive to a moderate water depletion. Surprisingly, we found no provenance $\times$ drought interactions, which leads to the conclusion that all provenances presented similar sensitivities to the stress. The validity of this conclusion is nevertheless limited by the fact that the climate was rather mild during our experiments, as compared to the field conditions of semi-arid Africa. It would be appropriate to examine this interaction under higher drought intensities and longer duration of stress.

Growth and water-use were reduced by drought. Relative biomass allocation to roots was improved during drought in all provenances (at the expense of stems and branches, since LMR remained unchanged). The main effect of drought on dry matter production and water-use was thus mediated by reductions in total 
leaf area, as well as by decreased stomatal conductance and net assimilation rates.

Relationships between $W$ and $\Delta$ can be diverse in $\mathrm{C}_{3}$ species, especially in situations of water limitation [16]. Drought usually decreases $\Delta$ and increases $A / g$ [14, 39]. The significant reduction in $\Delta$ observed here is consistent with the enhancement observed in $\mathrm{A} / \mathrm{g}$, suggesting that local and instant gas exchange measurements were truly accounted for by integrated values of $\Delta$. However, $\Delta$ was not correlated with $A / g$ in the dry treatment, and negatively correlated with $A / g$ when all treatments were confounded. Such variations were also presented by Donovan and Ehleringer [5] on Chrysothamnus nauseosus, and could find explanation in the fact that drought was imposed lately, or that allocation of biomass to the roots was higher during drought.

Surprisingly, $W$ was not affected by drought, contrary to $\Delta$ and $A / g$, and consequently two different relationships were found between $W$ and $\Delta$ under the two watering regimes. This apparent discrepancy, which was also reported in sunflower [33], or in cotton cultivars [16] can be explained by the fact that drought raises $v$ owing to stomatal closure and leaf temperature increase [3], thus limiting the increase of $W$. Concurrently to this effect, respiratory carbon loss may be enhanced during drought. However, $\Delta$ remains a valid indicator of $W$ under both watering regimes, since the rankings among provenances for $\Delta$ were not affected by drought.

\subsection{Consequences for the interpretation of field trials}

Studies on range-wide genetic variations in $\Delta$ and $W$ are rare $[29,40]$. The interpopulation (i.e. ecotypic) variability is thought to reflect differences in the environmental conditions to which plants are adapted [7]. We found significant differences in vigour, $W$ and $\Delta$ among the seven panafrican provenances of $F$. albida, and were able to distinguish two groups of provenances: south-east versus western African ones, on basis of several ecophysiological traits (table $I V$ ). The vigorous provenances display a rapid establishment during the wet seasons, transpiring more, with the help of larger leaf area, than the less vigourous ones. Unexpectedly, they also showed a higher water-use efficiency, confirmed by a lower $\Delta$. On the contrary, low $W$ in slow-growing provenances, accompanied by low SLA and TLA, can correspond to a strategy of achieving a higher assimilation per unit leaf area when mild-stress occurs [16, 29].

Differences in vigour, total leaf area and water-use probably played a main role during field trials in semi-arid regions: the vigorous provenances of $F$. albida displayed the lowest survival rates after one or two dry seasons (sometimes below $30 \%$ [2]). Vigorous initial growth is probably not a decisive advantage for $F$. albida under such conditions. Poor root growth with respect to shoot growth has often been suspected to be one of the causes for differences in survival: Vandenbeldt [32] found three-times longer roots in western provenances as compared to southern ones during trials on sandy soils in Niger. Marunda [25] confirmed similar tendencies with potted plants. Our results did not support this view. We propose a hypothesis to explain the poor survival of the most vigorous provenances: during establishment, they rapidly install their leaf area, use the water available in the upper soil layers, and could thus be submitted to drought stress and shed leaves earlier. As a result, their reserves could limit their survival. 
Table IV. Main traits opposing Faidherbia albida provenances (south-eastern versus western Africa).

\begin{tabular}{lcc}
\hline & S-E Provenances & W Provenances \\
\hline Survival in dry zones & low & high \\
Initial vigour and water-use & high & low \\
Total leaf area (TLA) & high & low \\
Leaf area-to-total dry mass ratio (LAR) & low & high \\
Specific leaf area (SLA) & high & low \\
Water-use efficiency $(W)$ & high & low \\
Carbon isotope discrimination $(\Delta)$ & low & high \\
\hline
\end{tabular}

\subsection{Selection perspectives}

We believe the growth of the rooting system of this phreatophytic species is the first component of the success of its establishment. During the juvenile stage, the water economy, which is mainly under control of the total leaf area, is also crucial. Concerning the possible use of $W$ as a selection criterion, it must be kept in mind that selecting for the most water efficient genotypes would lead to increase the vigour and the leaf area. This option would be dangerous if the water table is deep, but it could be justified otherwise.

The measured genetical variability in $W$ was substantial (magnitude $=1.36$ ). The fraction of intra-provenance variability (cumulated with error $=1-r^{2}$ ) was high: it was $50 \%$ in $W$ and $69 \%$ in $\Delta$, suggesting that eventual selection could be operated on provenances and on isolated genotypes. Ranking for $W$ was consistent with initial growth, and our results matched the second condition listed in the Introduction (no negative interaction between growth, water-use and $W$ ). The positive correlations between $W$, TLA, and vigour, the predictability of $W$ by $\Delta$ or LMR, are worth noting and correspond to a much sought-after combination of physiological features [3]. We found no provenance $\times$ drought interactions for $\mathrm{W}$ and $\Delta$, but further studies are required, in order to assess effects of nutrient availability, of climate and of severe drought. Despite these positive premises, the heritability of $W$ and $\Delta$ remains to be assessed, and the low survival in arid conditions of vigorous provenances displaying high $W$ must be more documented before associating $W$ to other traits of selection of $F$. albida. In particular $F$. albida is a multipurpose tree species, and one of its most important features, apart from forage yield, is its fruit production.

\section{CONCLUSION}

We may conclude that i) an important inter-provenance variability in initial growth and biomass allocation occurs among provenances of $F$. albida; ii) vigour is positively correlated with total leaf area, with transpiration, and negatively with LMR (leaf mass ratio); and iii) the most vigorous provenances presented higher values of $W$, and lower carbon isotope discrimination $(\Delta)$, but they probably display a lower survival in arid conditions. The relationships obtained here have nevertheless to be confirmed under various environments, and the heritability of $W$ to be assessed. If so, $\Delta$ is potentially a useful tool for screening genotypes of $F$. albida during the juvenile stages, but subordinated to other main criteria: efficiency of the rooting system and leaf area establishment. 


\section{ACKNOWLEDGEMENTS}

The authors are deeply indebted to J.M. Guehl for having introduced them into the world of carbon isotope discrimination and for helpful discussions and suggestions during the whole work. J.H. Desjeunes and J.M. Gioria provided skillful technical assistance in running the experiment, monitoring water-use and measuring plant biomass. Useful suggestions were made by C. Picon. O.R. was supported by a Ph. D. grant of the CIRAD-Forêt.

\section{REFERENCES}

[1] Bastide B., Diallo O.B., Comparaison de provenances de Faidherbia albida en plantation au Burkina-Faso, in: R. Peltier (Ed.) Les parcs à Faidherbia, CIRAD-Forêt, Cahiers scientifiques no. 12, Montpellier, 1996, pp. 259-268.

[2] Billand A., De Framond H., Variabilité génétique d'Acacia albida (synonyme Faidherbia albida) en essais comparatifs de provenances au Burkina-Faso, in: Riedacker A., Dreyer E., Joly H.I., Bory G. (Eds.), Physiologie des arbres et arbustes en zones arides et semi-arides, John Libbey Eurotext, Paris, 1993, pp. 235-248.

[3] Condon A.G., Richards R.A., Exploiting genetic variation in transpiration efficiency in wheat: an agronomic view, in: Ehleringer J.R., Hall A.E., Farquhar G.D. (Eds.), Stable isotopes and Plant Carbon-Water relations, Academic Press, San Diego, 1993, pp. $435-450$.

[4] Condon A.G., Farquhar G.D., Richards R.A., Genotypic variation in carbon isotope discrimination and transpiration efficiency in wheat. Leaf gas exchange and whole plant studies, Aust. J. Plant. Physiol. 17 (1990) 9-22.

[5] Donovan L.A., Ehleringer J.R., Potential for selection of plants for water-use efficiency as estimated by carbon isotope discrimination, Am. J. Bot. 81, 7 (1994) 927-935.

[6] Dupuy N.C., Dreyfus B.L., Bradyrhizobium populations occur in deep soil under the leguminous tree Acacia albida, Appl. Environ. Microb. 588 (1992) 2415-2419.

[7] Ehleringer J.R., Carbon and water relations in desert plants: an isotopic perspective, in: Ehleringer J.R., Hall A.E., Farquhar G.D., (Eds.), Stable Isotopes and Plant CarbonWater relations, Academic Press, San Diego, 1993, pp. 155-172.

[8] Farquhar G.D., Richards R.A., Isotopic composition of plant carbon correlates with water- use efficiency of wheat genotypes, Aust. J. Plant. Physiol. 11 (1984) 539-552.

[9] Farquhar G.D., O'Leary M.H., Berry J.A., On the relationship between carbon isotope discrimination and the intercellular carbon dioxide concentration in leaves, Aust. J. Plant. Physiol. 9 (1982) 121-137.

[10] Farquhar G.D., Ehleringer J.R., Hubick K.T., Carbon isotope discrimination and photosynthesis, Annu. Rev. Plant. Physiol. Plant. Mol. Biol. 40 (1989) 503-537.

[1 1] Flanagan L.B., Johnsen K.H., Genetic variation in carbon isotope discrimination and its relationship to growth under field conditions in full-sib families of Picea mariana, Can. J. For. Res. 25 (1995) 39-47.

[12] Guehl J.M., Picon C., Aussenac G., Gross P., Interactive effects of elevated $\mathrm{CO}_{2}$ and soil drought on growth and transpiration efficiency and its determinants in two European forest tree species, Tree Physiol. 14 (1994) 707-724.

[13] Gueh1 J.M., NGuyen-Queyrens A., Loustau D. and Ferhi A., Genetic and environmental determinants of water-use efficiency and carbon isotope discrimination in forest trees, in: Sandermann H., Bonnet-Masimbert M. (Eds.), Eurosilva: Contribution to Forest Tree Physiology, Inra Éditions Les Colloques 76 , 1995, pp. 298-321

[14] Hall A.E., Mutters R.G., Farquhar G.D., Genotypic and drought-induced differences in carbon isotope discrimination and gas exchange of cowpea, Crop. Sci. 32 (1992) $1-6$.

[15] Harmand J.M., Njiti C.F., Faidherbia albida in Northern Cameroon: Provenance trials and crop associations, in: Vandenbeldt R.J. (Ed.), Faidherbia albida in the West African SemiArid Tropics: Proceedings of a workshop, ICRISAT-ICRAF, 1992, pp. 79-82.

[16] Hubick K.T., Gibson A., Diversity in the relationship between carbon isotope discrimination and transpiration efficiency when water is limited, in: Ehleringer J.R., Hall A.E., Far quhar G.D. (Eds.), Stable Isotopes and Plant Carbon-Water Relations, Academic Press, San Diego, 1993, pp. 311-325.

[17] Hubick K.T., Farquhar G.D., Shorter (R), Correlation between water-use efficiency and carbon isotope discrimination in diverse peanut (Arachis) germplasm, Aust. J. Plant Physiol. 13 (1986) 803-816.

[18] Hubick K.T., Shorter R. and Farquhar G.D., Heritability and genotype $x$ environment interactions in carbon isotope discrimination and transpiration efficiency of peanuts (Arachis hypogea L), Aust. J. Plant. Physiol. 15 (1988) 799-813. 
[19] Ismail A.M., Hall A.E., Inheritance of carbon isotope discrimination and water-use efficiency in cowpea, Crop. Sci. 33 (1993) $498-503$.

[20] Johnson D.A., Asay K.H., Tieszen J.R., Ehleringer J.R., Jefferson P.G., Carbon isotope discrimination-potential in screening cool-season grasses for water-limited environments, Crop. Sci. 30 (1990) 607-615.

[21] Johnson D.A., Asay K.H., Read J.J., Genotypic and environmental variations for carbon isotope discrimination in crested wheatgrass, a perennial forage grass, in: Ehleringer J.R., Hall A.E., Farquhar G.D. (Eds.), Stable Isotopes and Plant Carbon-Water Relations, Academic Press, San Diego, 1993, pp. 269-280.

[22] Joly H.I., Zeh-Nlo M., Danthu P., Aygalent C., Population genetics of an African Acacia, Acacia albida. Genetic diversity of populations from West Africa, Aust. J. Bot. 40 (1992) 59-73.

123] Martin B., Thorstenson Y.R., Stable carbon isotope composition $\left(\delta^{13} \mathrm{C}\right)$, water-use efficiency and biomas productivity of Lycopersicon esculentum, Lycopersicon pennellii, and the Fl hybrid, Plant Physiol. 88 (1988) $218-223$

124] Marino B.S. and Mc Elroy M.B., Isotopic composition of atmospheric $\mathrm{CO}_{2}$ inferred from carbon in $\mathrm{C}_{4}$ plant cellulose, Nature 349 (1991) 127-131

[25] Marunda C.T., Geographical variation and physiological studies in Faidherbia albida (Del.) A. Chev. (syn Acacia albida Del), MSc thesis, Australian National University Department Forestry.

[26] Masle J., Farqhuar G.D., Effects of soil strength on the relation of water use efficiency and growth to carbon isotope discrimination an wheat seedlings. Plant Physiol. 86 (1988) 32-38.

[27] Meinzer F.C., Goldstein G., Grantz D.A., Carbon isotope discrimination and gas exchange in Coffee during adjustment to different soil moisture regimes, in: Ehleringer J.R., Hall A.E., Farquhar G.D. (Eds.), Stable Isotopes and Plant Carbon-Water Relations, Academic Press, San Diego, 1993, pp. 327-345.

[28] Poorter H., Remkes C., Leaf area ratio and net assimilation rate of 24 wild species dif fering in relative growth rate, Oecologia 8 (1990) 553-559.

[29] Read J., Farquhar J.R., Comparative studies in Nothofagus (Fagaceae). I. Leaf carbon isotope discrimination, Func1. Ecol. 5 (1991) 684-695.

[30] Sneizko R.A., Stewart H.T.L., Range-wide provenance variation in growth and nutrition of Acacia albida seedlings propagated in Zimbabwe, For. Ecol. Manag. 27 (1989) 179-197.

131| Torrekens P., Lemane I., Gambo S., Trial of nine Acacia albida provenances in Dosso, Niger, in: Vandenbeldt R.J. (Ed.), Faidherbia albida in the West African Semi-Arid Tropics: Proceedings of a Workshop, ICRISATICRAF, 1992, pp. 77-89.

[32] Vandenbeldt R.J., Problems with range-wide provenance trials of Faidherbia albida on sandy soils in Niger, in: Vandenbeldt R.J. (Ed,), Faidherbia albida in the West African Semi Arid Tropics: Proceedings of a Workshop, ICRISAT-ICRAF, 1992, pp. 83-86.

[33] Virgona J.M., Hubick K.T., Rawson H.M., Farqhuar G.D., Downes R.W., Genotypic variation in transpiration efficiency, carbonisotope discrimination and carbon allocation during early growth in sunflower, Aust. J Plant. Physiol. 17 (1990) 207-214.

134] Von Caemmerer S., Farquhar G.D., Some relationships between the biochemistry of photosynthesis and the gas-exchange of leaves, Planta 153 (1981) 376-387.

[35] Ward J.D., Breen C.M., Drought stress and the demise of Acacia albida along the lower Kuiseb River, Central Namib Desert: preliminary findings, South African J. Sci. 79 (1983) 444-447.

136] White J.W., Castillo J.A., Ehleringer J.R., Associations between productivity, root growth and carbon isotope discrimination in Phaseolus vulgaris under water deficit, Aust. J. Plant. Physiol. 17 (1990) 189-198.

137] Wickens G.E.. A study of Acacia albida Del. (Mimosoideae), Kew Bull. 23 (1969) 181-202.

[38] Wright G.C., Hubick K.T., Farquhar G.D., Nageswara Rao R.C., Genetic and environmental variation in transpiration efficiency and its correlation with carbon isotope discrimination and specific leaf area in peanut, in: Ehleringer J.R., Hall A.E., Farquhar G.D., (Eds.), Stable Isotopes and Plant CarbonWater Relations, Academic Press, San Diego, 1993, pp. 247-268.

[39] Zhang J., Marshall J.D., Population differences in water-use efficiency of well-watered and water-stressed western larch seedlings, Can. J. For. Res. 24 (1994) 92-99.

[40] Zhang J., Marshall J.D., Jaquish B.C., Genetic differentiation in carbon isotope discrimination and gas exchange in Pseudotsuga menziesii. A common garden experiment, Oecologia 93 (1993) 80-87.

[4I] Yoneyama T., Ohtani T., Variation of natural ${ }^{13} \mathrm{C}$ abundances in leguminous plants, Plant. Cell. Physiol. 24 (1983) 971-977. 